\section{Working together in the wetlands}

\author{
G.J. Wainwright
}

Sweet Track to Glastonbury: The Somerset Levels in Prehistory. By Bryony and John Coles. Thames \& Hudson:1986. Pp.200. £18.

THE research and educational value of archaeology lies in its multidisciplinary character; the subject draws upon specialists from the biological and physical sciences and brings them together with those whose primary concern is the study of past human cultures. Nowhere is this fusion better exemplified than in the study of wetlands; in the past two decades, this has developed into one of the most pressing areas of international research.

In this book - the twelfth in a series dealing with advances in our understanding of the human past - Bryony and John Coles describe their pioneering work in the Somerset Levels of south-west Britain. The field and publication programme has been in progress since 1963 , through the Coles' Somerset Levels Project. It is justly regarded as being very influential in its research directions and methodology, and has served as a model for research in the wetlands of Europe and North America. The book does justice not only to the importance of the subject but to the high reputation of its authors as innovators and managers of the complex multidisciplinary studies that wetland studies generate.

The core of the book describes the recognition and subsequent work upon the prehistoric wooden trackways, including the Sweet Track - the oldest road in the world. These trackways were built from before $3000 \mathrm{BC}$ and connected the small islands of higher ground which projected above the marsh. Investigation of them has provided a new understanding of early human society, its organization and economic base, and the sophisticated fashion in which the people of the time managed the available natural resources through manipulation of their environment. Because of the very nature of wetlands, organic remains are preserved - sometimes these are spectacular, such as the bog burials of northern Europe. More relevant to this project are the palaeoenvironmental studies of pollen, macro-fossils, coleoptera, diatoms and mollisscs; the involvement of dendrochronological and radiocarbon laboratories; and the conservation of waterlogged timbers over 5,000 years old.

Apart from containing thorough accounts of these various facets of the project, the book also conveys the message that, as a result of land recla- mation schemes and exploitation for minerals, the wetlands of the world are a diminishing scientific asset. This is now recognized by English Heritage which supports a number of projects to rescue the evidence before it is destroyed. Moreover, the clear message to emerge is that this response, although worthy, is inadequate: a representative sample of wetlands should also be conserved for the enjoyment and instruction of future generations. The range of interests represented by them is so broad that only the establishment of a Wetland Resource Centre will suffice to mobilize the multidisciplinary expertise necessary for such an enterprise. The particular value of this attractive and compelling book is that it will bring this need to the attention of a wide public. In all, one hopes that it will lay the foundation for a cooperative venture on an international scale, and both authors and publisher are to be congratulated on their enterprise.

G.J. Wainwright is Principal Inspector at the Historic Buildings and Monuments Commission for England, 23 Savile Row, London WIX $2 H E, U K$.

\section{HB one hundred}

\section{A. Robert Neurath}

Hepatitis B. Edited by Robert J. Gerety. Academic:1985. Pp.470. \$87, £72.50.

THE first epidemic of hepatitis B (HB) recognizable as such, occurred about 100 years ago. Only 80 years later, in 1965 , did the discovery of Australia antigen ( $=\mathrm{HB}$ surface antigen; $\mathrm{HBsAg}$ ) and its association with $\mathrm{HB}$ provide the basis for scientific attack on the disease. Failure to find an in vitro tissue culture system for replication of the $\mathrm{HB}$ virus (HBV) then retarded progress in unravelling its biology until 1979 , when the problem was in part overcome by the successful cloning of HBV DNA and the expression of $\mathrm{HBV}$ proteins in eukaryotic and prokaryotic cells transfected with HBV rDNA

In this book, our accumulated knowledge of all aspects of $\mathrm{HB}$ is comprehensively and succinctly summarized in 18 chapters contributed by 19 authors. The editor characterizes the endeavour as an "attempt to write a definitive book on the subject". Considering the vigour of research on $\mathrm{HB}$ and the number of outstanding questions concerning the molecular biology of HBV, the immunopathogenesis, therapy and prophylaxis of $\mathrm{HB}$, and the association of $\mathrm{HB}$ with primary hepatocellular carcinoma, such an attempt is not entirely realistic. This limitation is recognized by most of the authors, who devote adequate space to unresolved issues and future prospects.
The book is not without its defects, among them an unnecessary degree of repetition of material. There is, too, other evidence of lack of editorial firmness in that a number of contradictory statements are left hanging. This is acceptable when the differences are subjective (to drink or not to drink alcohol when infected with $\mathrm{HBV}$ ), but disturbing when scientific data are described: according to Table II in Chapter 4, small $\mathrm{HB}$ e antigen ( $\mathrm{HBeAg}$ ) has a molecular weight of about $100 \mathrm{kD}$ and is associated with albumin; but in Chapter 14 we learn that the molecular weight is $35 \mathrm{kD}$ (with an incorrect reference).

The second and third chapters, describing $\mathrm{HBsAg}$ and $\mathrm{HBcAg}$, respectively, would have benefited from more detailed consideration of the variety of immunoassays for these two antigens and the corresponding antibodies. Moreover, the characterization of $\mathrm{HBsAg}$ and $\mathrm{HBcAg}$, dealt with again in Chapters 14,17 and 18 , is imprecise - the fact that saccharides are present in $\mathrm{HBsAg}$ is not mentioned; the data on its polypeptide composition are outdated. The $\mathrm{N}$-terminal 140 amino acids of the HBcAg polypeptide do not have a protamine-like structure. In fact, the C-terminal portion of $\mathrm{HBcAg}$ has such properties. The competitive RIA for anti$\mathrm{HBc}$ most commonly used utilizes ${ }^{125} \mathrm{I}$ anti-HBc rather than ${ }^{125} \mathrm{I}-\mathrm{HBcAg}$ (p.39).

Chapter 4 is a comprehensive report on $\mathrm{HBeAg}$. However, the authors seem not to have been fully aware of certain related work carried out outside their laboratory. They also wonder about the origin of " $\mathrm{e}$ " in $\mathrm{HBeAg}$ - it corresponds, in fact, to the first letter of the second author's name (Espmark) in the paper describing the discovery of $\mathrm{HBeAg}$. The hypothesis that glutaraldehyde-polymerized albumin mediates the attachment of HBV to hepatocytes is untenable.

The chapters describing HB vaccines do not give recognition to the finding that distinct vaccines differ in efficiency when administered to immunocompromised recipients.

Notwithstanding these shortcomings, and the fact that little attention is given to genetic factors and to immunoregulatory mechanisms influencing the immune response to HBV, the book must be counted a success. Researchers in a wide variety of disciplines contribute to unravelling the mystery of hepatitis B. All of them virologists, epidemiologists, immunologists, physicians and oncologists, not to mention those in public health organizations, blood banks and producers of vaccines, blood derivatives and diagnostic reagents - will find it helpful both for reference and as background reading .

A. Robert Neurath is Head of the Laboratory of Biochemical Virology, The Lindsley F. Kimball Research Institute of The New York Blood Center, New York, New York 10021, USA. 